\title{
Laboratory profile in serologically proven dengue in children
}

\author{
Lokanatha H. ${ }^{1}$, Siddavatam S. ${ }^{2}$, Rudramurthy P. ${ }^{3}$, Sangappa M. ${ }^{4}$, Benakappa A.D. ${ }^{5}$ \\ ${ }^{1}$ Dr. Hemalata Lokanatha, Associate Professor, Department of Pathology, ${ }^{2}$ Dr. Supriya Siddavatam, Senior Resident, \\ Department of Pathology, ${ }^{3}$ Dr. Pradeep Rudramurthy, Assistant Professor, Department of Pathology, ${ }^{4}$ Dr. Mahantesh \\ Sangappa, Associate Professor, Department of Microbiology, ${ }^{5}$ Dr. Asha D Benakappa, Professor \& Director, Department \\ of Paediatrics, above all authors are affiliated with Indira Gandhi Institute of Child Health, Bangalore, Karnataka, India.
}

Address for Correspondence: Dr. Pradeep Rudramurthy, Assistant Professor, Department of Pathology, Indira Gandhi Institute of Child Health, Bangalore, Karnataka, India, Email : docpradi@gmail.com

\begin{abstract}
Introduction: Dengue is a mosquito borne infection caused by flavivirus and prevalent for more than a century in tropical countries. The aim of the study is to correlate hematological, biochemical and radiological parameters in serologically proven children of dengue at a tertiary care pediatric institute. Material and Methods: A study was done on 100 children with dengue up to 18 years of age admitted to our hospital. The serological tests used for diagnosis were NS1 antigen (rapid test) and IgM antibody detection by ELISA. Children were categorized into non-severe and severe dengue based on clinical features. Laboratory parameters were analyzed in these children. Result: Out of 100 children, 78 were categorized as non-severe dengue which included dengue fever (both with and without warning signs) and 22 children of severe dengue which included children of DHF and DSS as per WHO 2009 guidelines. Among hematological parameters, hemoconcentration, leukopenia, thrombocytopenia, presence of reactive lymphocytes in the peripheral smear, prolonged prothrombin time and activated partial thromboplastic time were useful indicators. Among biochemical parameters, raised SGOT and SGPT were seen both in severe and non-severe children. SGOT was found to be more elevated than SGPT. Gall bladder thickening was the commonest radiological finding followed by pleural effusion and ascites. Case fatality rate was $6 \%$. Conclusion: Dengue infection is responsible for frequent epidemics with fatal outcome especially in the pediatric age group. The highly complex and non-specific presentation of dengue infection highlights the importance of laboratory testing which will help in improving the outcome.
\end{abstract}

Key words: Non-severe dengue, Severe dengue, Thrombocytopenia, Children

\section{Introduction}

Dengue fever is one of the most important viral infections causing frequent epidemics in various parts of India [1]. It is caused by single stranded RNA virus of the Flaviviridae family. In India, all the four serotypes of the virus have been isolated [1]. Aedes aegypti and Aedes albopticus are the common vectors. World Health Organization (WHO) has estimated that 50 -100 million dengue infections occur every year [2]. The first case of Dengue was reported in Vellore in 1956 and Calcutta was the first place to report DHF in 1963 [3]. Case Fatality Rate, according to WHO is approximately 5\% [2]. According to some reports, the case fatality rate can be as high as $44 \%$ in severe

Manuscript received: $20^{\text {th }}$ February 2017

Reviewed: $2^{\text {nd }}$ March 2017

Author Corrected: $11^{\text {th }}$ March 2017

Accepted for Publication: $18^{\text {th }}$ March 2017
Dengue $[3,4]$. If diagnosis and treatment is done early, case fatality rate is less than $1 \%$ [5]. Dengue reinfection is more common in children [6]. Since ours is an exclusive pediatric institute, the study was undertaken to assess the hematological parameters, biochemical and radiological parameters in serologically proven Dengue in children up to 18 years of age.

\section{Material and Methods}

An observational study was done on 100 children of serologically proven Dengue children of up to 18 years of age admitted to Indiragandhi Institute of Child Health, Bangalore, Karnataka, India. All children who had fever for atleast 3 days duration and who tested positive for dengue infection were included in the 
Research Article

study. Children who had fever, but were negative for dengue testing were excluded from the study. Serological tests used for the diagnosis were NS1 antigen using Denguecombo rapid kit manufactured by TULIP diagnostics and IgM antibody assay was carried out by NIV DENMAC kit (version 2.4) by ELISA method. Based on the clinical features, children were classified into Dengue fever (with and without warning signs) and severe dengue fever (DHF, DSS) as per WHO 2009 guidelines [3]. Dengue fever was defined by high fever, fever with rash, myalgia, arthralgia, retro-orbital pain and conjunctival congestion. DHF included 3 criteria: hemorrhagic manifestations, platelet count of less than $1.0 \times 10^{6} / \mathrm{uL}$, ascites and pleural effusion indicating plasma leakage. Clinically, DSS was defined by features of shock in the form of rapid weak pulse, severe hypotension with systolic pressure less than $90 \mathrm{~mm}$ of $\mathrm{Hg}$. Complete blood count was done by using Mindray 5200BC 5 part differential cell counter. Prothrombin Time (PT) and Activated Partial Thromboplastin Time (APTT) were done by using KC1 coagulometer. Liver function tests were done by using fully automated Beckman AU480 analyzer. Abdominal ultrasound scan was done for the evaluation of pleural effusion and ascites in DSS.

Statistics: All the data was collected and analysed by using proportion test to test the significance of proportion. Any $\mathrm{P}$ value $</=0.05$ was considered to be statistically significant.

\section{Results}

We studied 100 children of serologically proven dengue, in children up to 18 years of age. Out of 100 children, 78 were categorized as non-severe which included dengue fever (both with and without warning signs) and 22 children of severe dengue which included children of DHF and DSS as per WHO 2009 guidelines [3]. Male to female ratio observed was 1.56:1. Youngest child in the study was 5 months old and the oldest child was 17 years of age as shown in Table $\mathbf{1}$.

Table- 1: Age and Gender distribution of the children in the study.

\begin{tabular}{|c|c|c|c|c|}
\hline Parameter & Variables & Numbers & Non-severe dengue & Severe dengue \\
\hline Age & $0-3$ years & 29 & 24 & 5 \\
\hline & $4-6$ years & 25 & 16 & 3 \\
\hline & $7-9$ years & 18 & 15 & 1 \\
\hline & $10-12$ years & 11 & 10 & 1 \\
\hline & $13-15$ years & 13 & 3 & $\mathbf{2 2}$ \\
\hline & $16-18$ years & 4 & $\mathbf{7 8}$ & 16 \\
\hline
\end{tabular}

Majority of the children were admitted in the rainy season in the months of July and August.

All the laboratory parameters with p values as summarized in Table 2

Hematocrit is one of the important findings of dengue which was raised both in non-severe and severe dengue and was statistically significant ( $p$ value $<0.05$ ) but it was difficult to demonstrate the rise below the baseline hematocrit in our study. The hematocrit value did not vary much from non-severe to severe dengue. Leukopenia was not a significant finding in our study as majority of the children had normal leukocyte count ( $\mathrm{p}$ value $>0.05$ ).

Thrombocytopenia was one of the important findings which helped in diagnosis and also to predict the severity as high proportion of severe dengue $(54.54 \%)$ had severe thrombocytopenia $\left(<50 \times 10^{3} / \mu 1\right)$ compared to $34.6 \%$ of non-severe dengue. Thrombocytopenia was seen in $67(85.89 \%)$ children of non-severe and $19(86.36 \%)$ children of severe dengue which was statistically significant ( $\mathrm{p}$ value 0.001 ). Four of the children with severe thrombocytopenia had other complications like pleural effusion, ascites. Among the liver enzymes, SGOT was elevated in larger proportion of children when compared to SGPT. Both showed significant P-value (SGOT 0.001 and SGPT <0.05). SGOT was very high $(>1000 \mathrm{IU} / \mathrm{L})$ in four patients whereas, SGPT was very high $(>1000 \mathrm{IU} / \mathrm{L})$ in two patients. 
Research Article

Table- 2: Laboratory profile and statistical analysis of all the children in the study.

\begin{tabular}{|c|c|c|c|}
\hline Investigations & Category & $\begin{array}{c}\text { Non-severe } \\
\text { dengue }(n=78)\end{array}$ & Severe dengue $(n=22)$ \\
\hline \multirow[t]{2}{*}{ Hematocrit } & $<36 \%$ & $25(32.1 \%)$ & $7(31.8 \%)$ \\
\hline & $>36 \%$ & $53(67.9 \%)$ & $15(68.2 \%)$ \\
\hline p-value & & 0.001 & 0.016 \\
\hline \multirow[t]{2}{*}{ Total Leukocyte count } & Leukopenia $<4 \times 10^{3} / \mu 1$ & $22(28.2 \%)$ & $2(9.09 \%)$ \\
\hline & Normal TLC $4 \times 10^{3} / \mu 1-11 \times 10^{3} / \mu 1$ & $56(71.8 \%)$ & $20(90.9 \%)$ \\
\hline p-value & & $>0.05$ & $>0.05$ \\
\hline \multirow[t]{2}{*}{ Platelet count } & $<150 \times 10^{3} / \mu 1$ & $67(85.9 \%)$ & $19(86.4 \%)$ \\
\hline & $>150 \times 10^{3} / \mu 1$ & $11(14.1 \%)$ & $3(13.6 \%)$ \\
\hline p-value & & 0.001 & 0.001 \\
\hline \multirow[t]{2}{*}{ Peripheral smear } & Reactive lymphocytes present & $73(93.5 \%)$ & $21(95.45 \%)$ \\
\hline & Reactive lymphocytes absent & $05(6.5 \%)$ & $1(4.55 \%)$ \\
\hline p-value & & 0.001 & 0.001 \\
\hline \multirow[t]{2}{*}{ PT } & Normal & $60(76.9 \%)$ & $5(22.7 \%)$ \\
\hline & Prolonged & $18(23.1 \%)$ & $17(77.3 \%)$ \\
\hline p-value & & $>0.05$ & 0.001 \\
\hline \multirow[t]{2}{*}{ APTT } & Normal & $8(10.2 \%)$ & $2(9.09 \%)$ \\
\hline & Prolonged & $70(89.7 \%)$ & $20(90.9 \%)$ \\
\hline p-value & & 0.001 & 0.001 \\
\hline \multirow{2}{*}{ SGOT(IU/L) } & $<40$ & $3(3.85 \%)$ & $2(9.09 \%)$ \\
\hline & $>40$ & $75(96.15 \%)$ & $20(90.91 \%)$ \\
\hline $\mathrm{p}$-value & & 0.001 & 0.001 \\
\hline \multirow[t]{2}{*}{ SGPT(IU/L) } & $<40$ & $30(38.5 \%)$ & $7(31.8 \%)$ \\
\hline & $>40$ & $48(61.5 \%)$ & $15(68.2 \%)$ \\
\hline p-value & & 0.004 & 0.016 \\
\hline \multicolumn{4}{|l|}{ Ultrasound abdomen } \\
\hline \multirow[t]{2}{*}{ Thickened gall bladder } & Present & $56(71.7 \%)$ & $19(86.3 \%)$ \\
\hline & Absent & $22(28.3 \%)$ & $3(13.7)$ \\
\hline p-value & & 0.001 & 0.001 \\
\hline \multirow[t]{2}{*}{ Hepatomegaly } & Present & $53(67.9 \%)$ & $19(86.36 \%)$ \\
\hline & Absent & $25(32.1 \%)$ & $3(13.64 \%)$ \\
\hline p-value & & 0.001 & 0.001 \\
\hline \multirow[t]{2}{*}{ Ascites } & Present & $34(43.5 \%)$ & $13(59.1 \%)$ \\
\hline & Absent & $44(56.5 \%)$ & $9(40.9 \%)$ \\
\hline $\mathrm{p}$-value & & $>0.05$ & $>0.05$ \\
\hline \multirow[t]{2}{*}{ Pleural effusion } & Present & $35(44.8 \%)$ & $17(77.2 \%)$ \\
\hline & Absent & $43(55.2 \%)$ & $5(22.8 \%)$ \\
\hline p-value & & $>0.05$ & 0.003 \\
\hline
\end{tabular}

Peripheral smear examination done by experienced pathologists revealed presence of reactive lymphocytes which were large, plasmacytoid having abundant basophilic cytoplasm with eccentric nucleus in majority of dengue children and was statistically significant ( $\mathrm{p}$ value 0.001). The coagulation profile parameters like PT and APTT were also analysed. PT was normal in $60(76.92 \%)$ children of non-severe dengue and prolonged in $17(77.27 \%)$ children of severe dengue and 
Research Article

was statistically significant ( $\mathrm{p}$ value 0.001 ) in severe dengue, whereas, APTT was prolonged in $70(89.74 \%$ ) children of non-severe dengue, and $20(90.90 \%)$ children of severe dengue which was statistically significant (p value 0.001$) .86 .3 \%$ ( $p$ value 0.001 ) of severe dengue children had gall bladder edema and $77.2 \%$ ( $p$ value 0.003 ) of severe dengue had pleural effusion by ultrasound examination which were statistically significant whereas hepatomegaly was a significant finding in non-severe and severe dengue children ( $\mathrm{p}$ value 0.001 ).

\section{Discussion}

Dengue is the world's fastest growing mosquito borne disease currently threatening half of the world's population. Infection with any one of the four serotypes DEN1, DEN2, DEN3, DEN4, confers immunity to that particular serotype, paving way for the person to get infected upto 4 times [7]. Recently, there is a surge in the incidence of dengue fever all over the world [5].There are very few studies from exclusive pediatric hospitals based on the revised new dengue classification by WHO in 2009. The literature studied so far points towards the fact that children are most affected by dengue mosquito. Hence, the present study was undertaken. Based on the WHO 2009 guidelines, in our study, 100 children were analyzed, out of which 78 were categorized into non-severe dengue which included dengue fever (without and with warning signs) and 22 belonged to severe dengue category.

Maximum numbers of children (72) were below 10 years of age with the youngest child being 5 months of age and the oldest was 17 years old. The male to female ratio of 1.56:1 was not statistically significant. The age and gender wise distribution varied with different studies. In a study by Shubhankar Mishra et al, maximum numbers of children were seen in the group more than 11 years of age and the least affected group was infants [8].

In a study by Kulkarni et al., the commonest age affected was 6-12 years with male preponderance [9]. In a study by Anju et al., $56 \%$ children were aged more than 6 years [10]. In a study by C.V Prathyusha et al., the common age group affected were between 9-12 years with almost equal male: female ratio [11]. Thus the varying age groups and insignificant male: female ratio in the patients affected by dengue infection in different studies, shows that dengue infection does not discriminate between people on the basis of gender or age which will justify our findings of age and gender distribution as depicted in the Table 1. DHF is more common in children than in adults and the incidence of DHF is bimodal with peaks at 7 months of age and 3 to 5 years of age [7]. In our study, more number of severe dengue children were seen in 0-3 years ( 5 children) and
4-6 years (9 children) which is in common with other studies [7]. More number of severe cases between 0-3 years could be due to the fact that infants who have acquired maternal dengue antibodies will develop DHF when they subsequently get infected by the virus [12]. On the other hand, DHF can occur in little older children between 3 to 5 years of age during the second infection which will explain our finding of severe dengue cases between 4-6 years. The greater baseline microvascular permeability is suggested to be the reason why DHF is more frequent in children [13]. DHF or DSS may also occur during primary infection, which may be due to virulent virus strain rather than antibody status due to previous infection. Anti-dengue antibodies from the previous infection will cross react with new infecting virus serotype and cause increased viral uptake by monocyte and macrophage. This antibody dependent mechanism causes amplified cascade of cytokines and complement activation which results in dysfunction of endothelial cells along with consumption of coagulation factors leading to plasma leakage and hemorrhagic manifestations. The virus serotype, age of the patient, and degree of viremia determine the severity of the disease [14]. All these above factors determine the severity of dengue.

Hemoconcentration is a very important factor. The raised hematocrit is an accurate indicator of vascular permeability and plasma leakage. Hematocrit was $>36 \%$ in $68.2 \%$ children of severe dengue and $67.9 \%$ children of non-severe dengue. Thus, according to our study, increased Hct does not vary much between nonsevere and severe dengue. According to Saha et al., [15] Hct may not be a good indicator in infants and children in presence of moderate anemia. According to Shubhankar et al [8] the children with hemoconcentration were low in proportion. Other previous studies also reported that fluid leakage does not achieve a high degree of hemoconcentration inspite of the patient being in shock because of associated anemia and blood loss. There is a lack of clear cut guidelines for hemoconcentration in the Indian population [8]. A lesser than expected rise in hematocrit has been found in other studies [16,17] making it important to develop 
Research Article

new guidelines for hemoconcentration and its use in the diagnosis and treatment $[10,17,18]$. Non-availability of pre-infection hematocrit, high prevalence of anemia in the Indian population [18], fall of hematocrit due to the blood loss, are the various pitfalls of taking hematocrit as a diagnostic or prognostic marker. The presence of hemoconcentration is useful for diagnosis of dengue, but the absence of hemoconcentration may not rule out dengue.

Leucopenia was seen in $22(28.2 \%)$ children of nonsevere and $2(9.09 \%)$ children of severe dengue. Leucopenia was not significantly related with the severity of dengue which was in agreement with the studies by Shubhankar et al[8] and Saha et al [15] where in leucopenia was seen in both non-severe and severe dengue children. Prathyusha et al [11] reported that, there was no significant association of leucopenia with bleeding manifestations or severity of dengue. Abhinav et al [19] found that leucocyte changes are poor indicators of severity, but are useful in differentiating dengue infections from other febrile illnesses [17].

$85.9 \%$ of children presented with thrombocytopenia (platelets less than $150 \times 10^{3} / \mu \mathrm{L}$ ). Severe thrombocytopenia (Platelets $<50 \times 10^{3} / \mu \mathrm{L}$ ) was seen in high proportion $(54.54 \%)$ of children with severe dengue compared to $34.6 \%$ of non-severe dengue. The above findings indicate that thrombocytopenia is a very useful parameter for diagnosis and severe thrombocytopenia predicts the severity of the dengue infection.

This finding was in concordance with Shubhankar et al., [20], C.V. Prathyusha [11], Abhinav et al [19] and Saha et al [15]. Thrombocytopenia is attributed to following causes like decreased production by the bone marrow [21], virus antigen-antibody complex mediated destruction [22] or increased consumption of platelets induced by secondary infection associated with the release of high level of platelet activating factors or increased adhesion of platelets to endothelial cells of vasculature [23].

The presence of reactive lymphocytes was seen in $73(93.5 \%)$ of non-severe and $21(95.45 \%)$ children of severe dengue. The above findings indicate that the presence of reactive lymphocytes is very useful marker for the diagnosis of dengue infection. Rashmi et al [8] reported similar findings. PT was normal in majority (76.9\%) of non-severe dengue children and prolonged in maximum $(77.3 \%)$ children of severe dengue, whereas APTT was prolonged both in non-severe $(89.7 \%)$ and $90.9 \%$ children of severe dengue. In our study, prolonged APTT was more consistent finding than prolonged PT. Prolonged PT/APTT can lead to bleeding manifestations apart from thrombocytopenia, decreased platelet function and fibrinogen consumption and vasculopathy [25] whereas Shubhankar Mishra et al [8] reported prolonged PT and APTT in $23.7 \%$ patients of non-severe dengue and $76.9 \%$ of severe dengue children in his study. Rise in PT/APTT is indicative of severity of disease.

In our study, SGOT was raised quantitatively more than the SGPT, which corroborated with the findings of Shubhankar Mishra et al [8]. In a study by $\mathrm{C} \mathrm{V}$ Prathyusha et al [11], hepatic dysfunction was seen in $17.5 \%$ children, comparable to the study done by Dhooria et al [26] in which it was seen in $14.8 \%$. The cause in such rise has been attributed to ischemic hepatitis or virus induced liver damage [27]. Banerjee et al [28] reported an increase in SGOT and SGPT levels in $60 \%$ of children and Dutta et al [29] have reported SGOT was raised in $68.5 \%$ and SGPT in $39.2 \%$ children. Lei et al found that patients with dengue virus infection have more increased RANTES (Regulated on Activation, Normal T Cell Expressed and Secreted), serum levels compared to other viral infection [30].

As RANTES is a chemokine capable of recruiting lymphocytes and NK cells to inflammatory sites, whether liver damage in dengue virus infection is an indirect effect of RANTES or a direct effect of virus replication needs further evaluation [24]. In the present study, gall bladder thickening, hepatomegaly and pleural effusion were significant ultrasound findings of severe dengue infection which were in agreement with other studies by Setiawan MW et al and Quiroz-Moreno $\mathrm{R}$ et al [31, 32]. The USG finding of gall bladder thickening more than $5 \mathrm{~mm}$ has been proven to be a useful marker for identification of hypovolemic shock [31] the pathophysiology of dengue fever being endothelial inflammation causing increased capillary leakage will explain the USG findings [33].

In our study, all the patients with non-severe dengue recovered and 6 patients out of 22 children of severe dengue died due to intractable shock. The case fatality rate in our study was $6 \%$ comparable to studies by Anju et al. [10], and Prathyusha et al [11] who also reported case fatality rate of $6 \%$. However, the case fatality rate 
can vary, as Shah et al reported a case fatality rate as high as $16.6 \%$ [34]. The outcome mainly depends on the early detection and proper management. Dengue has become a common disease recently with more ominous presentation in the pediatric age group.

Mortality from dengue are preventable with appropriate and timely medical attention. Our study emphasizes the role and importance of hematological, serological, biochemical parameters along with abdominal ultrasonography findings in helping the clinician to establish the disease, grade and its severity and prognosticating the condition of the child, leading to a rational approach to case management and a good clinical outcome.

Funding: Nil, Conflict of interest: None initiated, Permission from IRB: Yes

\section{References}

1. Ministry of Health and Family welfare: Guidelines for Clinical Management of Dengue Fever, Dengue Hemorrhagic Fever and Dengue Shock Syndrome. New Delhi, India: Govt of India. 2008: 2-14.

2. WHO, "Denue and Dengue Hemorrhagic fever," Factsheet no.117, World Health Organization,Geneva, Switzerland.2008, http://www. who. int/mediacentre/ factsheets /fs117/en/.

3. Special Programme for Research,Training in Tropical Diseases, and World Health Organization, Dengue: Guidelines for Diagnosis, Treatment, Prevention and Control, World Health Organization, Geneva, Switzerland, 2009.

4. Rigau-P'erez JG, Clark GG, Gubler DJ, Reiter P, Sanders EJ, Vorndam AV. Dengue and dengue haemorrhagic fever, Lancet. 1998 Sep 19;352(9132): 971-7.

5. World Health Organization, "WHO report on global surveillance of Epidemic prone infectious diseases," http://apps.who.int/iris/bitstream/10665/66485/1/WHO CDS CSR ISR 2000.1.pdf.

6. Wichmann O, Hongsiriwon S, Bowonwatanuwong C, Chotivanich K, Sukthana Y, Pukrittayakamee S. Risk factors and clinical features associated with severe dengue infection in adults and children during the 2001 epidemic in Chonburi, Thailand. Trop Med Int Health. 2004 Sep;9(9):1022-9.
7. Guzmán MG, Kourí G. Dengue: an update. Lancet Infect Dis. 2002 Jan;2(1):33-42.

8. Mishra S, Ramanathan R, and Agarwalla SK. Clinical Profile of Dengue Fever in Children : A study from Southern Odisha, India. Scientifica. Vol.2016, Article ID 6391594, 6 pages doi: 10.1155/2016/ 6391594.

9. Kulkarni, M.J., Sarathi V, Bhalla V, Shirpuri D, and Achary U. Clinico-Epidemiological Profile of Children Hospitalised with Dengue. Indian J Pediatr 2010; 77: 1103-1107.

10. Aggarwal A, Chandra J, Aneja S, Patwari AK, Dutta AK. An epidemic of dengue hemorrhagic fever and dengue shock syndrome in children in Delhi. Indian Pediatr. 1998 Aug;35(8):727-32.

11. Prathyusha CV, Rao MS, Sudarsini $\mathrm{P}$ and Umamaheshwara Rao K. Clinico-haematological profile and outcome of dengue fever in children. Int $\mathbf{J}$ Curr Microbiol Appl Sci 2013; 2(10): 338-346.

12. Kliks SC, Nimmanitya S, Nisalak A, Burke DS. Evidence that maternal dengue antibodies are important in the development of dengue hemorrhagic fever in infants. Am J Trop Med Hyg. 1988 Mar;38(2):411-9.

13. Gamble J, Bethell D, Day NPJ, et al. Age-related changes in microvascular permeability: A significant factor in the susceptibility of children to shock?. Clin Sci 2000; 98: 211-6.

14. Sumaro W, Jahja E, Gubler DJ, Suharyono W, Sorensen K. Clinical observations on virologically confirmed fatal dengue infections in Jakarta, Indonesia. Bull WHO 1983; 61; 920-929.

15. Saha KA, Shibendu G. Clinico-Pathological profile in the infants and children in dengue 2012 epidemic, Kolkata. Int J Med Res Health Sci 2014; 3(1) : 59-64.

16. Narayanan M, Aravind MA, Thilothammal N, Prema R, Sargunam CS, Ramamurty N. Dengue fever epidemic in Chennai--a study of clinical profile and outcome. Indian Pediatr. 2002 Nov;39(11):1027-33.

17. Kalayanarooj S, Vaughn DW, Nimmannitya S, Green S, Suntayakorn S, Kunentrasai N, Viramitrachai 
W, Ratanachu-eke S, Kiatpolpoj S, Innis BL, Rothman AL, Nisalak A, Ennis FA. Early clinical and laboratory indicators of acute dengue illness. J Infect Dis. 1997 Aug;176(2):313-21.

18. Gomber S, Ramachandran V, Kumar S et al. hematological observations as diagnostic markers in dengue hemorrhagic fever -a reappraisal. Indian pediatr 2001;38: 477-481.

19. Jain A, Shah NA, Patel P, Desai M, Somani S, Parikh $\mathrm{P}$ et al. A Clinico-Hematological profile of Dengue outbreak among healthcare professionals in a tertiary care hospital of Ahmedabad with analysis on economic impact. National journal of community medicine 2013; 4(2): 286-290.

20. Ratageri VH, Shepur TA, Wari PK, Chavan SC, Mujahid IB, Yergolkar PN. Clinical profile and outcome of Dengue fever cases. Indian J Pediatr. 2005 Aug; 72 (8):705-6.

21. Halstead SB. Antibody, macrophages, dengue virus infection, shock, and hemorrhage: a pathogenetic cascade. Rev Infect Dis. 1989 May-Jun;11 Suppl 4: S830-9.

22. Wang S, He R, Patarapotikul J, Innis BL, Anderson R. Antibody-enhanced binding of dengue- 2 virus to human platelets. Virology. 1995 Oct 20;213(1):254-7.

23. Yang KD, Wang CL, Shaio MF. Production of cytokines and platelet activating factor in secondary dengue virus infection. J Infect Dis. 1995; 172:604.

24. Rashmi MV and Hamsaveena. Haematological and biochemical markers as predictors of dengue infection. Malays J pathol 2015; 37(3) : 247-251.

25. Mittal H, Faridi MMA, Arora SK, and Patil R, "Clinicohematological profile and platelet trends in children with dengue during 2010 epidemic in North India”. Indian J Pediatr.2012;79(4) : 467-471.

26. Dhooria G S, Bhat D, Bias H S. Clinical profile and outcome in children of Dengue fever in North India. Iran J Ped 2008;18(03): 222-28.

27. Bhaskar M, Moorthy S, Kumar NS, Arthur P. Dengue hemorrhagic fever among adults-An observational study in Chennai,south India. Indian J Med Res.2010 Dec; 132(6): 738-740.

28. Banerjee M, Chatterjee T, Choudary GS, Srinivas V, Kataria V K,. Dengue: A clinic-hematological profile. MJFAI. 2008; 64(4): 333-6.

29. Dutta p, Khan SA, Borah J, Mahanta J. Demographic and clinical features of patients with Dengue in North -eastern region of India: A retrospective cross-sectional study during 2009-2011. J Virol Microbiol 2012 DOI: 10.5171/2012. 786298.

30. Lei HY, Yeh TM, Liu HS, Lin YS, Chen SH, Liu CC. Immunopathogenesis of dengue virus infection. J Biomed Sci. 2001 Sep;8(5):377-88.

31. Setiawan MW, Samsi TK, Pool TN, Sugianto D, Wulur H. Gallbladder wall thickening in dengue hemorrhagic fever: an ultrasonographic study. J Clin Ultrasound. 1995 Jul-Aug;23(6):357-62.

32. Quiroz-Moreno R, Méndez GF, Ovando-Rivera KM. [Clinical utility of ultrasound in the identification of dengue hemorrhagic fever]. Rev Med Inst Mex Seguro Soc. 2006 May-Jun;44(3):243-8.

33. Halstead SB. Dengue: hematologic aspects. Semin Hematol. 1982 Apr;19(2):116-31.

34. Shah I, Deshpande GC, Tardeja PN. Outbreak of dengue in Mumbai and predictive markers for dengue shock syndrome. J Trop Pediatr. 2004 Oct;50(5):301-5.

\section{How to cite this article?}

Lokanatha H, Siddavatam S, Rudramurthy P, Sangappa M, Benakappa A.D. Laboratory profile in serologically proven dengue in children.Trop J Path Micro 2017;3(2):181-187.doi: 10.17511/jopm.2017.i2.19. 